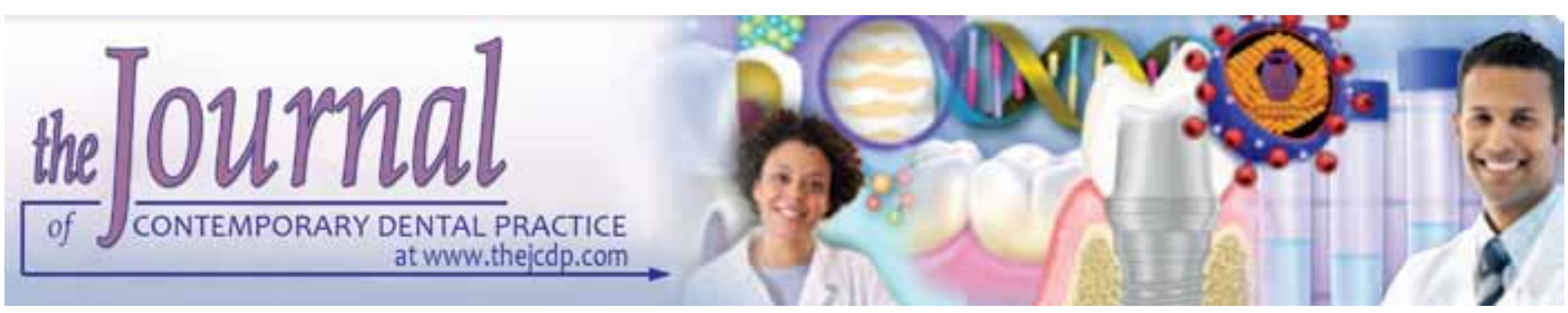

\title{
Evaluation of Microvascularity by CD34 Expression in Esophagus and Oral Squamous Cell Carcinoma
}

\author{
${ }^{1}$ Fatemeh Shahsavari, ${ }^{2}$ Sareh Farhadi, ${ }^{3}$ Donia Sadri, ${ }^{4}$ Marzieh Sedehi
}

\begin{abstract}
Aim: The present study was scheduled to evaluate microvascularity by CD34 expression in esophagus and oral squamous cell carcinoma.

Materials and methods: This study was scheduled using 40 paraffin blocked samples including 20 of oral SCC and 20 of esophagus ones and Immunohistochemical staining was conducted using CD34 monoclonal antibody. Exact fisher test was used to evaluate frequency of expression between two studied groups.
\end{abstract}

Results: There was significant correlation between age and tumor size with CD34 expression in oral SCC samples ( $p<$ 0.05 ) and no significant correlation between sex and tumor differentiation level (grading) ( $p>0.05$ ). Also, there was no significant correlation between age, sex, tumor size and tumor differentiation level (grading) with CD34 expression in esophagus SCC samples ( $p>0.05)$. There was no significant difference of CD34 expression frequency in oral and esophagus $\operatorname{SCC}(p=0 / 583)$. Finally, CD34 expression was reported 'high' for major cases of esophagus and oral SCCs.

Conclusion: It seems, other angiogenetic or nonangiogenetic factors except CD34 may play more important role and explain the different clinical behavior of SCC at recent different locations.

Clinical significance: Other factors would be considered along with CD34 expression to interpret different clinical behavior of SCC at recent different locations.

Keywords: Angiogenesis, CD34, Esophagus squamous cell carcinoma, Micro vascularity, Oral squamous cell carcinoma.

\footnotetext{
${ }^{1-3}$ Department of Oral and Maxillofacial Pathology, Dental Branch of Tehran, Islamic Azad University, Tehran, Iran

${ }^{4}$ Private Practice, Tehran, Iran
}

Corresponding Author: Sareh Farhadi, Assistant Professor No. 177, Fifth Golestan St, Pasdaran St, Tehran, Iran, Phone: +98 21 22542238, e-mail: dr.sfarhadi@gmail.com
How to cite this article: Shahsavari F, Farhadi S, Sadri D, Sedehi M, Evaluation of Microvascularity by CD34 Expression in Esophagus and Oral Squamous Cell Carcinoma. J Contemp Dent Pract 2015;16(6):458-462.

Source of support: Nil

\section{Conflict of interest: None}

\section{INTRODUCTION}

Squamous cell carcinoma (SCC) is known as the most common esophagus and oral cancer. ${ }^{1,2}$ Recent surveillance epidemiology and end results data suggest that 28,900 new cases of oral squamous cell carcinoma (OSCC) will occur in the United States in 2007, and cause 7,400 OSCC-related deaths. ${ }^{3,4}$ The most common sites for oral SCC are buccal mucosa, tongue, palatal mucosa, lips and gingiva. In general, overall survival is considered as 5 years that is not improved since recent two decades. Unfortunately, this survival rate is known as the lowest between major recognizing cancers. ${ }^{5}$ By then, prediction of its biologic behavior may be an important factor in treatment plan of disease. Early diagnosis can increase the possibility of improvement ${ }^{2}$ but, prolonged diagnosis makes tumor progression and present social and economic complications. ${ }^{6}$ Esophageal cancer can be divided into esophageal squamous cell carcinoma (ESCC) and adenocarcinoma based on its etiological and histopathological classification, with about $50 \%$ of all ESCC cases in the world occurring in China. ${ }^{7}$ Esophagus squamous cell carcinoma is similar to oral ones but due possible delay in diagnosis refers to site of tumor, it usually detects in advanced stages with lymph node metastasis. ${ }^{8}$ However, owing to its aggressive nature, patients suffering from esophageal cancer usually present with local recurrence or distant metastasis after primary treatment. The 5 years survival rate of esophageal cancer patients, especially those diagnosed at advanced stages (i.e. stage III or IV), still remains disappointing. ${ }^{9}$ 
Several parameters have been clarified to rate of tumor progression. ${ }^{8}$ Nowadays, prediction of biologic behavior of SCC tumors is possible by evaluation of tumor markers expression. Indeed, CD34 expression is used as biomarker through clinical managing of tumors. ${ }^{1}$

CD34 is a membrane glycoprotein from Sialomucin protein family with molecular weight of 105 to 120 CDS. Antibody of Anti-CD34 is connected to membrane protein of Sialomucin. Then, it would enable to detect of endothelial cells whether in precursor form or mature cells. ${ }^{10}$ Evaluation of angiogenesis and detection of endothelial cells and also, distinguish of vascular channels through lymphatic ones would be difficult; but these problems are solute by cooperation of Immunohistochemical staining and easily report as micro vessel density (MVD). Angiogenesis has great importance through tumor progression. First, Algire then Folkman conducted some studies around this. ${ }^{11}$ Angiogenesis can be indicator of clinical outcome and tumor prognosis. ${ }^{10}$ There are few studies around evaluation and comparison of this expression in correlate with biologic behavior and pathological parameters of SCC samples. So, the present study was scheduled to evaluate microvascularity by CD34 expression in esophagus and OSCC.

\section{MATERIALS AND METHODS}

This study was scheduled using 40 paraffin blocked samples at pathology department of Dental branch, Azad Islamic University and Rasht Razi laboratory. Twenty samples of OSCC and 20 of this tumor in esophagus area with definite histopathological diagnosis, proper fixation processing, complete demographic information and enough tissue without great necrosis and hemorrhage were chosen and studied. From each selected block,

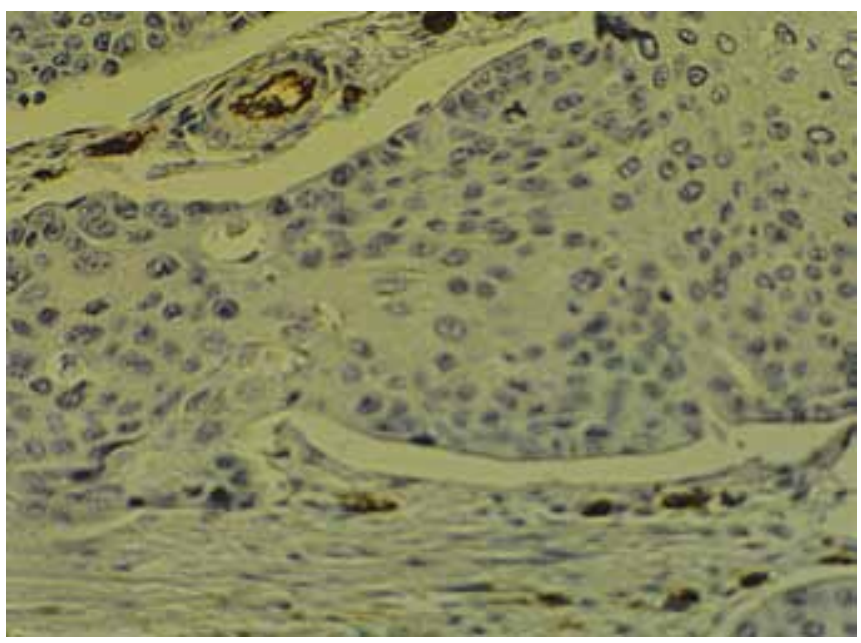

Fig. 1: Immunohistochemistry staining of CD34 in ESCC samples by 200 times magnification
2 sections of 3 to 4 micron were prepared in order to hematoxilin and eosin and immunohistochemical staining. At this step, all demographic information as sex and age of patients and also data related to tumor size, histopathologic grade and clinical stage were extracted and registered through information form. However, examiners did not notified about recent information though single blind design of this study.

Immunohistochemical staining was conducted using CD34 monoclonal antibody. Sections were prepared for staining by dehydration and deparafinization; then, heated at microwave for 10 minutes with fresh citrate HCL buffer $10 \mathrm{MM}, \mathrm{pH}=6$. After cooling them at room temperature, washed with phosphated-buffered saline (PBS) and incubated with antibody of CD34 antigen (0.1\% subtilty, Dako company) for 1 hour. Then, washed with PBS and incubated with piotinylated antibody and peroxidase labeled streptavidin, each for 30 minutes and closed with DAB chromogen ( 3,3 diamino benzidine hydrochloride) in order to detection of brown reaction product. Finally, sections were stained by ethyl—green and mounted for studying. Hemangioma and deletion of primary antibody were used for positive and negative control of staining respectively. ${ }^{12}$

Brown color of endothelial cells was designated as expression of CD34 marker and used for counting of vessels. By then, 10 microscopic fields with 400 times magnification were randomly chosen for evaluation and averages of counted vessels were registered. Figures 1 and 2 show immunohistochemistry staining of CD34 in esophagus and oral SCC samples, respectively. Also, the software of Imagefocuse capture ver. 2.5.2006 and Euromex microscope, Holland were used for more precise evaluation. Exact fisher test was used to evaluate frequency of expression between two studied groups.

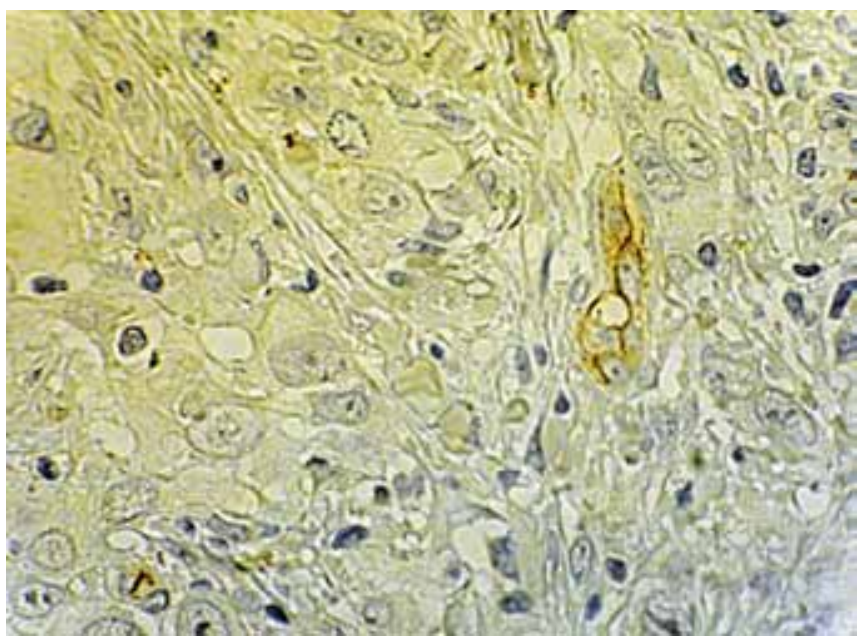

Fig. 2: Immunohistochemistry staining of CD34 in OSCC samples by 400 times magnification 


\begin{tabular}{|c|c|c|c|c|}
\hline Related factors & $\begin{array}{l}\text { CD34 low expression } \\
n(\%)\end{array}$ & $\begin{array}{l}\text { CD34 high expression } \\
n(\%)\end{array}$ & Total & $p$-value \\
\hline \multicolumn{5}{|l|}{ Age } \\
\hline$>65$ years old & $2(28.6 \%)$ & $10(83.3 \%)$ & $19(100 \%)$ & \multirow{3}{*}{0.029} \\
\hline$\leq 65$ years old & $5(71.4 \%)$ & $2(16.7 \%)$ & & \\
\hline Total & $7(100 \%)$ & $12(100 \%)$ & & \\
\hline \multicolumn{5}{|l|}{ Sex } \\
\hline Male & $4(57.1 \%)$ & $5(41.7 \%)$ & $19(100 \%)$ & \multirow{3}{*}{0.43} \\
\hline Female & $3(42.9 \%)$ & $7(58.3 \%)$ & & \\
\hline Total & $7(100 \%)$ & $12(100 \%)$ & & \\
\hline \multicolumn{5}{|c|}{ Tumor differentiation } \\
\hline Well & $6(85.7 \%)$ & $7(58.3 \%)$ & $19(100 \%)$ & \multirow{3}{*}{0.238} \\
\hline Poorly & $1(14.3 \%)$ & $5(41.7 \%)$ & & \\
\hline Total & $7(100 \%)$ & $12(100)$ & & \\
\hline \multicolumn{5}{|l|}{ Tumor Size } \\
\hline$\leq 2 \mathrm{~cm}$ & $4(57.1 \%)$ & $12(100 \%)$ & & \multirow{3}{*}{0.036} \\
\hline$>2 \mathrm{~cm}$ & $3(42.9 \%)$ & $0(0 \%)$ & $19(100 \%)$ & \\
\hline Total & $7(100 \%)$ & $12(100 \%)$ & & \\
\hline
\end{tabular}

Table 2: Frequency of CD34 expression and other related factors in ESCC samples

\begin{tabular}{|c|c|c|c|c|}
\hline Related factors & Low expression & High expression & Total & $p$-value \\
\hline \multicolumn{5}{|l|}{ Age } \\
\hline$>65$ years old & $2(28.6 \%)$ & $5(45.5 \%)$ & & \multirow{3}{*}{0.417} \\
\hline$\leq 65$ years old & $5(71.4 \%)$ & $6(54.5 \%)$ & $18(100 \%)$ & \\
\hline Total & $7(100 \%)$ & $11(100 \%)$ & & \\
\hline \multicolumn{5}{|l|}{ Sex } \\
\hline Male & $5(57.1 \%)$ & $8(72.7 \%)$ & $18(100 \%)$ & \multirow{3}{*}{0.676} \\
\hline Female & $2(28.6 \%)$ & $3(27.3 \%)$ & & \\
\hline Total & $7(100 \%)$ & $11(100 \%)$ & & \\
\hline \multicolumn{5}{|c|}{ Tumor differentiation } \\
\hline Well & $2(28.6 \%)$ & $3(27.3 \%)$ & & \multirow{3}{*}{0.676} \\
\hline Poorly & $5(71.4 \%)$ & $8(72.7 \%)$ & $18(100 \%)$ & \\
\hline Total & $7(100 \%)$ & $11(100 \%)$ & & \\
\hline \multicolumn{5}{|l|}{ Tumor size } \\
\hline$\leq 2 \mathrm{~cm}$ & $0(0 \%)$ & $0(0 \%)$ & & \multirow{3}{*}{-} \\
\hline$>2 \mathrm{~cm}$ & $7(100 \%)$ & $11(100 \%)$ & $18(100 \%)$ & \\
\hline Total & $7(100 \%)$ & $11(100 \%)$ & & \\
\hline
\end{tabular}

\section{RESULTS}

From 37 studied cases with age average of $65 \pm 13.5$ years old, $22(59.5 \%)$ males and $15(40.5 \%)$ females were present.

The present findings revealed that there was a significant correlation between age and tumor size with CD34 expression in OSCC samples $(\mathrm{p}<0.05)$. Although, there was no significant correlation between sex and tumor differentiation level (grading) $(\mathrm{p}>0.05)$ (Table 1).

Also, there was no significant correlation between age, sex, tumor size and tumor differentiation level (grading) with CD34 expression in ESCC samples ( $p$ > 0.05) (Table 2).

Fisher exact statistical test were used for evaluation and comparison of CD34 expression frequency in oral and ESCC; whether there was no significant correlation in this manner $(p=0 / 583)$.
CD34 expression were reported 'high' for 11 (61.1\%) of esophagus cases and 12 (63.2\%) of oral ones. The rest cases demonstrated low expression which had no significant difference between them $(\mathrm{p}>0.05)$ (Table 3).

\section{DISCUSSION}

Nowadays, the key to improving survival is to predict which early-stage tumors warrant further initial aggressive therapy. Angiogenesis is an important mechanism

Table 3: Frequency of CD34 expression in oral and esophagus SCC samples

\begin{tabular}{llll}
\hline $\begin{array}{l}\text { CD34 } \\
\text { expression }\end{array}$ & OSCC no (\%) & ESCC no (\%) & p-value \\
\hline Low & $7(36.8 \%)$ & $7(38.9 \%)$ & \\
High & $12(63 / 2 \%)$ & $11(61.1 \%)$ & 0.583 \\
Total & $19(100 \%)$ & $18(100 \%)$ & \\
\hline
\end{tabular}


to facilitate tumorigenic metastatic potential. The ability of a tumor to induce vascularization ensures adequate blood supply and nutrients for tumor growth and a mechanism for metastasis. So, tumor progression is critically dependent on intratumoral angiogenesis, which provides sufficient nutrients for invasive or metastatic tumors. It is widely accepted that, among the various angiogenic factors, vascular endothelial growth factor (VEGF) is an essential regulator of physiopathologic angiogenesis and correlates with increased MVD, advanced disease stage and poor prognosis of human cancers. ${ }^{13,14}$ The roles of other angiogenic factors are so far less clear; as Algire et $\mathrm{al}^{11}$ first recognized the concept of neovascularization and angiogenesis of tumor cells. During angiogenesis, CD34 binds to precursors of undifferentiated endothelial cells. $^{15,16}$

Although, there were some studies around expression of vascular markers and prognosis and clinical behavior of tumors but it seems no more evaluating and comparison of this in esophagus and oral squamous cell carcinoma focusing on correlation with clinical behavior of tumors.

The present finding corresponding to Chen et $\mathrm{al}^{12}$ and Ferreira et $\mathrm{al}^{17}$ reports showed that there was no significant correlation between CD34 expression and age, sex and tumor size at esophagus SCC samples. Li et $\mathrm{al}^{18}$ found that there was a higher CD34 expression in esophagus SCC samples vs normal mucosa. Probably, similar sample size of these studies cause to achieve the same results which intensify our report.

On the other hand, unlike to the present study there was a significant correlation between CD34 expression and stage, grade and lymph node metastasis in oral SCC samples in reports of Kademani et $\mathrm{al}^{19}$ and Eshghyar et $\mathrm{al}^{10}$ presenting significant correlation between angiogenetic factor (MVD) and lymph node metastasis in OSCC. However, we could not evaluate stage of tumors referring to insufficient related information. Few numbers of samples at every grade in the present study may affect this correlation and explain the difference.

However, Sabaghian et $\mathrm{al}^{20}$ in line with our study reported no significant correlation between angiogenetic factor (MVD) and grades of oral SCC. Guttman et $\mathrm{al}^{21}$ concluded more invasion of tumor by increased vascularity level in their study around oral cancers. Assessment of correlation between clinicopathological factors and vascular parameters may be challenging in order to scattered results, different evaluating methods and various vascular markers and it may explain the differences between results of studies.

\section{CONCLUSION}

It seems no significant difference between expression of CD34 angiogenetic factor in ESCC and OSCC samples. So, other angiogenetic or non-angiogenetic factors may play more important role in this manner and explain the different clinical behavior of these tumors.

\section{CLINICAL SIGNIFICANCE}

Other factors would be considered along with CD34 expression to interpret different clinical behavior of SCC at recent different locations.

\section{ACKNOWLEDGMENT}

We thank Dr Mahmoud Habibzadeh and Dr Alireza Mesbah from Razi Referral Pathology Lab, Guilan, Iran, for their advices on immunohistochemical processes of this study, and Dr Akhondi for statistical analysis.

\section{REFERENCES}

1. Kudo Y, Takata T, Yasui W, Ogawa I, Miyauchi M, Takekoshi T, Tahara E, Nikia H. Reduced expression of cyclin-depended kinase inhibitor P27 Kip1 is an indirector of malignant behavior in oral squamous cell carcinoma. Cancer 1998 Dec 15;83(12):2447-2455.

2. Yasusei K, Shojiro K, Ikuko O, Mutsumi M, Takashi T. Down regulation of Cdk inhibitor $\mathrm{P}_{27}$ in oral squamous cell carcinoma. Oral Oncology 2005 Feb;41(2):105-116.

3. Ries LAG, Harkins D, Krapcho M, et al: SEER Cancer Statistics Review, 1975-2003. Bethesda, MD, National Cancer Institute, 2005 [updated 2006; cited March and May 2006]. Available at: http:/ / seer.cancer.gov/csr/1975_2003/.

4. Mao L, Hong WK, Papadimitrakopoulou VA. Focus on head and neck cancer. Cancer Cell 2004;5:311.

5. Nagler R. Oral cancer-molecular aberrations and tumor marker cellular aberration. Harefuah 2003 Apr;142(4):272-276, 318, 317.

6. Nozoe T, Oyama T, Takenoyama M, Hanagiri T, Sugio K, Yasumoto K. Significance of immunohistochemical expression of $\mathrm{P}_{27}$ and involucrine as the maker of cellular differention of squamous cell carcinoma of the esophagus. Oncology 2006;71(5-6):402-410.

7. Stoner GD, Wang LS, Chen T. Chemoprevention of esophageal squamous cell carcinoma. Toxicol Appl Pharmacol 2007;224:337-349.

8. Nevil OB, Dam DD, Allen CM. Oral. Bouquot J and maxillofacial pathology. Philadelphia:Saunders.3rd ed;2009.p. 409-421.

9. Enzinger PC, Mayer RJ. Esophagealcancer. NEnglJ Med 2003;349:2241-2252.

10. Eshghyar NA, Motahari P, Rahroutaban S. Evaluation of microvascular density by CD34 in squamous cell carcinoma of the tongue and its relationship with cervical lymph node metastasis. J Dent Med Winter 2009;21[4(57)]:233-241.

11. Algire GH, Chalkley HW, Earle WE, et al: Vascular reactions of normal and malignant tissues in vivo. III. Vascular reactions of mice to fibroblasts treated in vitro with methylcholanthrene. JNCI 1950;11:555. 
12. Chen L, Luo G, Tan Y, Wei J, Wu C, Zheng L, Zhang X, Xu N. Immunolocalisation of tissue factor in esophageal cancer is correlated with intratumoral angiogenesis and prognosis of the patient. Acta Histochemical 2010 May;112(3):233-239.

13. Ferrara N, Davis-Smyth T. The biology of vascular endothelial growth factor. Endocr Rev 1997;18:4-25.

14. Toi M, Matsumoto T, Bando H. Vascular endo the lial growth factor: its prognostic, predictive, and the rapeutic implications. Lancet Oncol 2001;2:667-673.

15. Moriyama M, Kumagai S, Kawashiri S, et al: immunohistochemical study of tumour angiogenesis in oral squamous cell carcinoma. Oral Oncol 1997;33:369.

16. Schor AM, Pendleton N, Pazouki S, et al. assessment of vascularity in histological sections: Effects of methodology and value as an index of angiogenesis in breast tumours. Histochem J 1998;30:849.

17. Ferreira VA, Czeczko NG, Ribas FJM, Malafaria o, Ribas CA, Gomes CS, Cunha RM, Cuenca RM. CD34 and caspase-3 biomarkers expression in esophageal epidermoid carcinoma. Rev col Bras cir, 2009 Feb;36(1):35-41.

18. Li Z, Liu J, Tang F, Liu Y, Waldum HL, Cui G. Expression of non-mast cell histidine decarboxylase in tumor-associated microvessels in human esophageal squamous cell carcinomas APMIS 2008 Dec;116(12):1034-1042.

19. Kademani D, Lewis JT, Lamb DH, Rallis DJ, Harrington JR. Angiogenesis and CD34 expression as a predictor of recurrence in oral squamous cell carcinoma. J Oral Maxillofac Surg 2009 Sep;67(9):1800-1805.

20. Jahanshahi G1, Sabaghian M. Comparative immunohistochemical analysis of angiogenesis and mast cell density in oral normal mucosa and squamous cell carcinoma Dent Res J (Isfahan) 2012 Jan;9(1):8-12. doi: 10.4103/1735-3327.92920.

21. Guttman D, Stern Y, Shpitzer T, Ulanovski D, Druzd T, Feinmesser R. Expression of mmp-9, TIMP-1, CD34 and factor 8 as prognostic marker for squamous cell carcinoma of the tongue. Journal of APMIS 2004;116:1034-1042. 